\title{
Filipino Nursing Students' eHealth Literacy and Criteria Used for Selection of Health Websites
}

Ryan Michael F. Oducado ${ }^{1}$, Rome B. Moralista ${ }^{2}$

${ }^{1}$ West Visayas State University, Iloilo, Philippines

${ }^{2}$ Guimaras State College, Guimaras, Philippines

*Corresponding email: rmoducado@wvsu.edu.ph (Oducado)

\begin{abstract}
Possessing eHealth literacy skills among students has been increasingly appreciated in nursing education. Despite eHealth literacy has been widely studied, little published research is available regarding Filipino nursing students' eHealth literacy. This study aimed to determine the self-reported eHealth literacy of Filipino nursing students and the relative importance of the criteria they use when selecting health websites. A cross-sectional research design was used involving 66 conveniently chosen nursing students. Self-reported data were collected using adopted questionnaires. Data were analyzed using descriptive statistics, the Mann-Whitney U test, and Spearman's rho. Findings revealed that nursing students had high eHealth literacy. The utility of information and accuracy of information were the top criteria students consider important when selecting health websites. There were no significant differences in the eHealth literacy of male and female and first-year and second-year nursing students. The extent of Internet use for health information, perceived usefulness of the Internet when making health decisions, and perceived importance to access health resources on the Internet were significantly correlated with eHealth literacy. To derive full benefit from online health information, nursing students' literacy needs in the Web context and digital environment must be given attention.
\end{abstract}

Keywords: eHealth literacy, internet, nursing, students, Philippines

How to cite this article: Oducado RMF, Moralista RB (2020): Filipino nursing students' ehealth literacy and criteria used for selection of health websites, Ann Trop Med \& Public Health; 23(S13B): SP231343. DOI:

http://doi.org/10.36295/ASRO.2020.231343

\section{INTRODUCTION}

The Internet has become a major resource to access new knowledge and information related to health [13]. However, gaining access to these online health resources alone is insufficient [4]. Access to reliable health information was an identified issue in a survey conducted by the Health on the Net Foundation [5]. Even though access to health information on the Internet has created new opportunities to learn about health, people can easily become misinformed given the vast amount of online information that is subject to manipulation [6]. The Internet and social media are digital platforms whereby information or misinformation can be circulated. Hence, there is an ever-increasing need to check data sources and evaluate the credibility and reliability of health information available on the Internet [7]. The necessity to use and navigate the Internet with confidence is mainly important for problems and issues related to health where the implications and consequences for using inaccurate and low-quality information are big [4]. This is particularly essential in the Philippines wherein Filipinos are among the heaviest Internet users worldwide [8]. According to the Digital 2020 report from Hootsuite and We are Social, as of January 2020, there were 73 million Internet users in the Philippines accounting for more than half of the total population [9].

eHealth literacy is becoming more and more necessary for nursing students [10]. Aside from educating and training nursing students on how to assess and apply health literacy strategies [11], possessing Annals of Tropical Medicine \& Public Health http://doi.org/10.36295/ASRO.2020.231343 
eHealth literacy skills has been increasingly appreciated in nursing education. Nursing students should be able to successfully find, utilize, and evaluate available information on electronic platforms or possess eHealth literacy skills [2].

Meanwhile, the results of prior research on eHealth literacy conducted elsewhere are mixed. A review study noted that many college students were lacking eHealth literacy skills [12]. Graduate and students from medical departments had higher eHealth literacy than undergraduate and nonmedical students [13]. Among nursing student samples, a low or inadequate self-perceived level of eHealth literacy was reported in Ethiopia [14] and Sri Lanka [15] while moderate eHealth literacy was disclosed with nursing students in Jordan [2], Nepal [3], and Japan [16]. On the other hand, nursing students in Korea [10] and Denmark [17] reported satisfactory eHealth literacy. A comparison of American and Korean nursing students' eHealth literacy found that nursing students in the US posted higher mean scores of eHealth literacy [1]. The mixed results of previous researches suggest that eHealth literacy of students may vary across different countries that warrant investigation within a particular context.

Even if eHealth literacy has been studied by some nursing scholars, little published research is available regarding the eHealth literacy of nursing students in the Philippines. There is a need to pay interest and attention in meeting and improving nursing students' eHealth-literacy skills and needs $[3,15,16]$. Nursing students should have the necessary eHealth skills not only to empower and develop their patients' selfreliance to manage their own health [17] but also to enable themselves to make better and informed health decisions [2] and become health literate in the electronic world. This study assessed the eHealth literacy of nursing students in two nursing schools in the Philippines. It also determined the relative importance of the criteria they use when selecting health websites.

\section{METHODS}

A cross-sectional research design was adopted in this study. Sixty-six $(n=66)$ conveniently chosen nursing students in selected nursing schools in the Western Visayas region of the Philippines participated in the online survey. The $\mathrm{G}^{*}$ Power program suggested that a sample size of 84 is required given an alpha of 0.05 , power of 0.80 , and an effect size of 0.03 . The number of participants in this study is $78.57 \%$ of the required suggested sample size. Some scholars consider $50 \%$ as an acceptable response rate, although it is acknowledged that online surveys achieved much lower response rates [18]. The eHealth Literacy Scale (eHEALS) was adopted for data collection. The eHEALS is an 8-item scale designed to measure combined knowledge, comfort, and perceived skills at finding, evaluating, and applying electronic health information to health [4]. Items were answerable on a 5-point Likert scale with response options ranging from " $1=$ strongly disagree" to " $5=$ strongly agree". The eHEALS has an internal consistency of $\alpha=0.88$ [4]. For this study, the reliability of the scale was computed at $\alpha=0.93$. The criteria from the study of Escoffery and colleagues [19] were used to assess the relative importance of each criterion for selecting health websites. Students were asked to answer in a 3-point Likert scale with options ranging from "1 = not important" to " 3 = very important". Questions soliciting the socio-demographic data and general Internet usage of students were also included in the survey to gather relevant data needed for this study. To collect the data, students were invited by their respective nursing faculty to participate in the study via Facebook groups and messenger containing a link to the survey. The participants were instructed that upon proceeding with the survey, they grant consent to participate in the research voluntarily. Information about the purpose of the study was provided at the start of the online survey. Participants were also assured that they are not required nor forced to participate in the survey and data gathered will be treated confidentially and will be used for research purposes only. The data were analyzed with descriptive statistics, the Mann-Whitney U test, and Spearman's rho that were carried out using SPSS version 23 . The statistical significance was set at 0.05 alpha.

\section{Annals of Tropical Medicine \& Public Health http://doi.org/10.36295/ASR0.2020.231343}




\section{RESULTS}

Table 1 shows that a total of 66 (78.8\% second-year and $21.2 \%$ first-year) nursing students responded in the online survey with an average of 20.05 years. The majority of the students were female (69.7\%), commonly use smartphones or mobile devices to access the internet (87.9), and with an average daily usage of the Internet of 7.05 hours. The majority had somewhat stable Internet connection (47\%), often uses the Internet to search for health information (43.9\%), considers the Internet to be very useful when making decisions about health (40.9\%), and found that it was very important to access health resources on the Internet (56.7\%).

Table 1. Demographic and general internet patterns

\begin{tabular}{|c|c|c|c|c|}
\hline Categories & Mean & SD & $\mathrm{f}$ & $\%$ \\
\hline \multicolumn{5}{|l|}{ Sex } \\
\hline Male & & & 20 & 30.3 \\
\hline Female & & & 46 & 69.7 \\
\hline \multicolumn{5}{|l|}{ Year Level } \\
\hline First Year & & & 14 & 21.2 \\
\hline Second Year & & & 52 & 78.8 \\
\hline \multicolumn{5}{|l|}{ Device Used to Access the Internet } \\
\hline Smartphone & & & 58 & 87.9 \\
\hline Laptop & & & 6 & 9.1 \\
\hline Others & & & 2 & 3 \\
\hline Age (years) & 20.05 & 1.09 & & \\
\hline Hours of Internet Use (hours) & 7.05 & 3.90 & & \\
\hline Stability of Internet connection & 3.02 & 0.85 & & \\
\hline Very stable & & & 1 & 1.5 \\
\hline Stable & & & 18 & 27.3 \\
\hline Somewhat stable & & & 31 & 47.0 \\
\hline Not stable & & & 13 & 19.7 \\
\hline Not very stable & & & 3 & 3.5 \\
\hline Extent of Internet Use for Health Information & 3.91 & 0.97 & & \\
\hline Almost always & & & 19 & 28.8 \\
\hline Often & & & 29 & 43.9 \\
\hline Sometimes & & & 13 & 19.7 \\
\hline Rarely & & & 3 & 4.5 \\
\hline Almost never & & & 2 & 3.0 \\
\hline \multicolumn{5}{|l|}{ Decisions } \\
\hline Very useful & & & 27 & 40.9 \\
\hline Useful & & & 24 & 36.4 \\
\hline Unsure & & & 11 & 16.7 \\
\hline Not useful & & & 4 & 6.1 \\
\hline Not very useful & & & 0 & 0.0 \\
\hline Importance to Access Health Resources on the Internet & 4.41 & 0.84 & & \\
\hline Very important & & & 37 & 56.7 \\
\hline Important & & & 23 & 34.8 \\
\hline Unsure & & & 3 & 4.5 \\
\hline Not import & & & 2 & 3.0 \\
\hline
\end{tabular}

Annals of Tropical Medicine \& Public Health http://doi.org/10.36295/ASR0.2020.231343 
Table 2 shows the criteria for the selection of health websites. The top criteria nursing students considered important when selecting health websites were utility of information $(M=2.88$, Rank 1$)$ and accuracy of information ( $M=2.85$, Rank 2). These were followed by ease of understating and readability $(M=2.83$, Rank 3.5) and comprehensiveness of information $(M=2.82$, Rank 5$)$. On the other hand, nursing students least considered bias ( $M=1.91$, Rank 15) as important when selecting health websites.

Table 2. Importance of criteria for selection of health websites

\begin{tabular}{lccc}
\hline Criteria & Mean & SD & Rank \\
\hline Utility or usefulness of information & 2.88 & 0.33 & 1 \\
Accuracy of information & 2.85 & 0.36 & 2 \\
Ease of understanding & 2.83 & 0.38 & 3.5 \\
Readability & 2.83 & 0.38 & 3.5 \\
Comprehensiveness of information & 2.82 & 0.39 & 5 \\
Credibility of author & 2.80 & 0.40 & 6 \\
Currency of information & 2.73 & 0.45 & 7 \\
Citation of information & 2.71 & 0.49 & 8 \\
Quality of links & 2.59 & 0.58 & 9 \\
Confidentiality & 2.53 & 0.61 & 10 \\
Personal relevance & 2.52 & 0.61 & 11 \\
Use of multimedia & 2.47 & 0.56 & 12 \\
Interactivity & 2.32 & 0.71 & 13 \\
Appearance & 2.27 & 0.69 & 14 \\
Bias & 1.91 & 0.74 & 15 \\
\hline
\end{tabular}

Table 3 shows that generally, nursing students had high self-reported eHealth literacy $(M=4.02, S D=0.71)$.

Table 3.Self-reported eHealth literacy

\begin{tabular}{lcc}
\hline Level of eHealth Literacy (Mean=4.02, $\mathrm{SD}=0.71)$ & $\mathrm{f}$ & $\%$ \\
\hline High $(3.67-5.00)$ & 47 & 71.2 \\
Moderate (2.34-3.66) & 18 & 27.3 \\
Low (1.00-2.33) & 1 & 1.5 \\
\hline
\end{tabular}

Table 4 shows that the extent of use of the Internet for health information $(p=0.000)$, perceived usefulness of the Internet when making health decisions $(p=0.000)$, and perceived importance to access health resources on the Internet $(\mathrm{p}=0.007)$ were significantly correlated with eHealth literacy. On the other hand, hours of Internet use $(\mathrm{p}=0.079)$ and the stability of Internet connection $(\mathrm{p}=0.280)$ were not associated with eHealth literacy. Additionally, eHealth literacy did not significantly vary with sex $(\mathrm{p}=0.994)$ and year level $(\mathrm{p}=0.848)$. 
Table 4.Differences and correlation between variables

\begin{tabular}{|c|c|c|}
\hline Variables & Test statistics & p-value \\
\hline $\mathrm{Sex}^{\dagger}$ & 459.500 & 0.994 \\
\hline Year Level ${ }^{\dagger}$ & 319.500 & 0.848 \\
\hline Hours of Internet Use $\mathrm{f}^{\ddagger}$ & 0.218 & 0.079 \\
\hline Stability of Internet connection ${ }^{\neq}$ & 0.135 & 0.280 \\
\hline Extent of Internet Use for Health Information ${ }^{\ddagger}$ & 0.425 & $0.000^{*}$ \\
\hline Usefulness of the Internet when Making Health Decisions & 0.481 & $0.000^{*}$ \\
\hline Importance to Access Health Resources on the Internet ${ }^{\ddagger}$ & 0.328 & $0.007^{*}$ \\
\hline
\end{tabular}

Note: †Mann-Whitney $U$, ${ }^{\star}$ Spearman's rho, ${ }^{*} p<0.05$

\section{DISCUSSION}

This research assessed the eHealth literacy of nursing students. Likewise, it examined the criteria used by nursing students when selecting health websites. This study demonstrated that Filipino nursing students generally had high eHealth literacy. Nursing students in other countries like in Korea [10] and Denmark [17] also reported satisfactory and high eHealth literacy. Despite the majority had relatively high selfreported eHealth literacy, there were still students in this study who had a moderate level of eHealth literacy. Such a result provides a picture of potentially vulnerable students [20]. These students must be properly identified and must be given support and assistance by the nursing faculty in using eHealth to its fullest potential.

This study also found that nursing students frequently use the Internet for health information and consider the Internet to be a useful and important resource in accessing health information. These factors were also associated with eHealth literacy of nursing students. Similar to the findings of this study, nursing students in the US and South Korea [1] and Nepal [3] found the Internet to be useful in helping them make health-related decisions. Also, prior studies revealed that nursing students' frequency of using the Internet for health-related purposes, perception of the usefulness, and importance of the Internet were related to their eHealth literacy $[2,3,15]$. Norman \& Skinner argued that it is not unreasonable to assume an association between the use of technology in general and eHealth literacy [4]. The authors further explained that the more a person utilizes the technology, the more likely the person is going to develop and hone the skills in using that technology as a tool [4].

Contrary to the result of prior studies $[2,10,14]$, this study found no difference in the eHealth literacy of nursing students according to academic year level. Perhaps, in this current study, only two academic year levels were compared. Future research may be conducted to compare the eHealth literacy of students with other higher year levels in the undergraduate nursing program. This was not done in the current study as the educational system in the country has recently transitioned to the $\mathrm{K}$ to 12 program [21]. Most nursing schools in the Philippines have a limited number of third and fourth-year nursing students at the time of the survey. Furthermore, in this study, the eHealth literacy of students also did not vary based on sex. Similarly, gender did not significantly affect the eHealth literacy of Jordanian nursing students [2]. In contrast, gender was associated with eHealth literacy among nursing students in Ethiopia [14]. Additional research may be conducted to further validate gender differences in eHealth literacy among nursing students.

Despite prior studies reporting nursing students are lacking skills to evaluate online health information and cannot differentiate between high and low-quality resources on the Internet $[2,16,22]$, it is significant to note that the utility and accuracy of online information were considered by nursing students as the 
most important criteria in the selection of health websites along with ease of understanding, readability, comprehensiveness of information and credibility of the author. Correspondingly, credibility or the accuracy of the health information on health websites was a crucial consideration among university or college students conveyed from studies conducted elsewhere $[19,23]$. This finding is notable knowing that the quality of health information differed across websites and medical fields [24].

This study has limitations. The sample of this study was chosen conveniently and only involves two nursing schools and two-year levels in the Philippines. The relatively small sample size limits the generalizability of findings, thus findings are regarded as preliminary. There may also be response bias since data gathered in this study were self-reported. Further research may be conducted on a larger sample including other nursing students in the other parts of the country and internationally. Nevertheless, this study has provided valuable information regarding the eHealth literacy of nursing students in the Philippines.

\section{CONCLUSIONS}

Nursing students are generally eHealth literate, although there are still some with only a moderate level of eHealth literacy. Moreover, perceived usefulness and importance of the Internet and the extent of use of the Internet to access health information significantly influence nursing students' eHealth literacy. The more students use the Internet for health information, the more they consider it useful and important, the higher is their level of eHealth literacy. Nursing students should continually receive instructions, education, and training on eHealth literacy. Meeting the literacy needs of nursing students in the Web context and digital environment in the undergraduate program is thereby suggested to derive full benefit from online health information and for students to become health literate in the electronic world.

\section{ACKNOWLEDGMENT}

The authors would like to thank the participants of this study.

\section{CONFLICT OF INTEREST}

The authors declare no potential conflicts of interest with respect to the research, authorship, and/or publication of this article.

\section{REFERENCES}

[1] Park, H., \& Park, H. (2016). eHealth literacy skills among undergraduate nursing students in the US and South Korea. Studies in Health Technology and Informatics, 225, 899-900. https://doi.org/10.3233/978-1-61499-658-3-899

[2] Tubaishat, A., \& Habiballah, L. (2016). eHealth literacy among undergraduate nursing students. Nurse Education Today, 42, 47-52. https://doi.org/10.1016/j.nedt.2016.04.003

[3] Sharma, S., Oli, N., \& Thapa, B. (2019). Electronic health-literacy skills among nursing students. Advances in Medical Education and Practice, 10, 527. https://doi.org/10.2147/AMEP.S207353

[4] Norman, C. D., \& Skinner, H. A. (2006). eHEALS: The eHealth literacy scale. Journal of Medical Internet Research, 8(4), e27. http://dx.doi.org/10.2196/jmir.8.4.e27

[5] Cader, R. (2013). Judging nursing information on the world wide web. CIN: Computers, Informatics, Nursing, 31(2), 66-73. https://doi.org/10.1097/NXN.0b013e3182771880

[6] Swire-Thompson, B., \& Lazer, D. (2020). Public health and online misinformation: Challenges and recommendations. Annual Review of Public Health, 41, 433-451. https://doi.org/10.1146/annurevpublhealth-040119-094127

[7] Kanekar, A. S., \& Thombre, A. (2019). Fake medical news: Avoiding pitfalls and perils. Family Medicine and Community Health, 7, e000142. https://doi.org/10.1136/fmch-2019-000142

[8] Oducado, R. M. F. (2019). Gen Z nursing students' usage, perception and satisfaction with Facebook Annals of Tropical Medicine \& Public Health http://doi.org/10.36295/ASRO.2020.231343 
for educational purposes: Tool for learning or distraction. Indonesian Nursing Journal of Education and Clinic, 4(1), 79-89. http://dx.doi.org/10.24990/injec.v4i1.241

[9] Kemp, S. (2020). Digital 2020: The Philippines. Retrieved from https://datareportal.com/reports/digital-2020-philippines

[10] Kim, S., \& Jeon, J. (2020). Factors influencing eHealth literacy among Korean nursing students: A cross-sectional study. Nursing \& Health Sciences. https://doi.org/10.1111/nhs.12711

[11] Maduramente, T., Orendez, J., Saculo, J., Trinidad, A. L., \& Oducado, R. M. F. (2019). Health literacy: Knowledge and experience among senior students in a nursing college. Indonesian Nursing Journal of Education and Clinic, 4(1), 9-19. http://dx.doi.org/10.24990/injec.v4i1.227

[12] Stellefson, M., Hanik, B., Chaney, B., Chaney, D., Tennant, B., \& Chavarria, E. A. (2011). eHealth literacy among college students: A systematic review with implications for eHealth education. Journal of Medical Internet Research, 13(4), e102. https://doi.org/10.2196/jmir.1703

[13] Tsukahara, S., Yamaguchi, S., Igarashi, F., Uruma, R., Ikuina, N., Iwakura, K., Koizumi, K., \& Sato, Y. (2020). Association of eHealth literacy with lifestyle behaviors in university students: Questionnairebased cross-sectional study. Journal of Medical Internet Research, 22(6), e18155. http://dx.doi.org/10.2196/18155

[14] Shiferaw, K. B., Mehari, E. A., \& Eshete, T. (2020). eHealth literacy and internet use among undergraduate nursing students in a resource limited country: A cross-sectional study. Informatics in Medicine Unlocked, 18, 100273. https://doi.org/10.2147/AMEP.S205414

[15] Rathnayake, S., \& Senevirathna, A. (2019). Self-reported eHealth literacy skills among nursing students in Sri Lanka: A cross-sectional study. Nurse Education Today, 78, 50-56. https://doi.org/10.1016/j.nedt.2019.04.006

[16] Tanaka, J., Kuroda, H., Igawa, N., Sakurai, T., \& Ohnishi, M. (2020). Perceived eHealth literacy and learning experiences among Japanese undergraduate nursing students: A cross-sectional study. CIN: Computers, Informatics, Nursing, 38(4), 198-203. https://doi.org/10.1097/CIN.0000000000000611

[17] Holt, K. A., Overgaard, D., Engel, L. V., \& Kayser, L. (2020). Health literacy, digital literacy and eHealth literacy in Danish nursing students at entry and graduate level: A cross sectional study. BMC Nursing, 19, 1-12. https://doi.org/10.1186/s12912-020-00418-w

[18] Nulty, D. D. (2008). The adequacy of response rates to online and paper surveys: What can be done?.Assessment \& Evaluation in Higher Education, 33(3), 301-314. https://doi.org/10.1080/02602930701293231

[19] Escoffery, C., Miner, K. R., Adame, D. D., Butler, S., McCormick, L., \& Mendell, E. (2005). Internet use for health information among college students. Journal of American College Health, 53(4), 183-188. https://doi.org/10.3200/JACH.53.4.183-188

[20] Storey, A., Hanna, L., Missen, K., Hakman, N., Osborne, R. H., \& Beauchamp, A. (2020). The association between health literacy and self-rated health amongst Australian university students. Journal of Health Communication, 1-11. https://doi.org/10.1080/10810730.2020.1761913

[21] Oducado, R. M. F., Sales, M. R., Magarzo, A. J. P., Panes, P. M. A., \& Lapastora, J. T. P. (2019). Perceptions and attitude on using social media responsibly: Toward social media literacy in nursing education. Belitung Nursing Journal, 5(3), 116-122. https://doi.org/10.33546/bnj.789

[22] Park, H., \& Lee, E. (2015). Self-reported eHealth literacy among undergraduate nursing students in South Korea: A pilot study. Nurse Education Today, 35(2), 408-413. https://doi.org/10.1016/j.nedt.2014.10.022

[23] OseiAsibey, B., Agyemang, S., \&BoakyeDankwah, A. (2017). The internet use for health information seeking among Ghanaian university students: A cross-sectional study. International Journal of Telemedicine and Applications, Article ID 1756473. https://doi.org/10.1155/2017/1756473

[24] Zhang, Y., Sun, Y., \& Xie, B. (2015). Quality of health information for consumers on the web: A systematic review of indicators, criteria, tools, and evaluation results. Journal of the Association for Information Science and Technology, 66(10), 2071-2084. https://doi.org/10.1002/asi.23311

\section{Annals of Tropical Medicine \& Public Health http://doi.org/10.36295/ASR0.2020.231343}

